\title{
EDITORIAL
}

Adv Clin Exp Med 2014, 23, 5, 675-681

ISSN 1899-5276

(c) Copyright by Wroclaw Medical University

Barbara Krzywicka ${ }^{1, A-D, F}$, Katarzyna Herman $^{1, B-F}$,

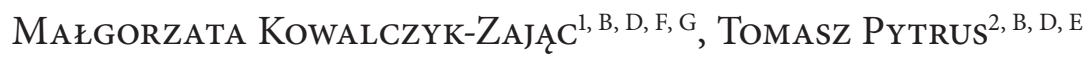

\section{Celiac Disease and Its Impact on the Oral Health Status - Review of the Literature}

${ }^{1}$ Department of Conservative Dentistry and Pedodontics, Wroclaw Medical University, Poland

${ }^{2}$ Department of Pediatrics, Gastroenterology and Nutrition, Wroclaw Medical University, Poland

A - research concept and design; $\mathbf{B}$ - collection and/or assembly of data; $\mathbf{C}$ - data analysis and interpretation;

$\mathbf{D}$ - writing the article; $\mathbf{E}$ - critical revision of the article; $\mathbf{F}$ - final approval of article; $\mathbf{G}$ - other

\begin{abstract}
The paper presents the most recent reports on celiac disease, especially its manifestations within the oral cavity. Particular attention should be paid to typical dental enamel defects with a various degree of advancement: discolorations, horizontal groves and pits, and even significant structural destruction causing the change of the dental crown. Symmetric location of defects within all dentition sections, and within the same anatomic groups of teeth (the most frequently: incisors and first permanent molars), is specific for celiac disease. The changes described above may be the only manifestation of celiac disease; therefore, in the case of their occurrence further studies towards gluten intolerance are recommended even when other symptoms are not present. In celiac patients, recurrent aphthae and other disorders of the oral mucosa such as ulceration, erythema, atrophic glossitis, as well as dryness and a burning sensation (particularly of the tongue) may be present, which may be caused by malnutrition. Delayed tooth eruption may also be a consequence of alimentary deficiency in celiac disease (Adv Clin Exp Med 2014, 23, 5, 675-681).
\end{abstract}

Key words: celiac disease, developmental enamel defects, aphthae, delayed tooth eruption.

Gluten-dependent celiac disease is an immune-mediated systemic disease which manifests itself with intolerance to gluten in the diet in people with genetic predisposition. Gluten is a protein contained in the grains of basic European cereals. In pathogenesis of celiac disease only a part of the gluten complex is significant: gliadin in wheat, secalin in rye, hordein in barley and avenin in oats [1]. The incidence of celiac disease in the general population is estimated to lie between 0.5 and 1\% [2]. The etiopathogenesis of the disease is multifactorial, and genetic and environmental factors are taken into consideration as the cause of the disease [3].

Tissue antigens expressed on the antigen presenting cell of class II - HLA DQ2 and HLA DQ8 are the most known genetic factors. Those antigens are responsible for presenting modified gluten proteins to T CD4+ lymohocytes, which leads to an improper immune response. This process takes place in the small intestine. In the human organism, gluten is not totally digested, but is only broken down to peptides which are transferred across the intestinal wall and are modified there by tissue transglutaminase (TTG). This enzyme is present in the organism in an inactivated form, and the cause of its activation in celiac disease remains unknown. The result of TTG action is the production of negatively charged peptide molecules which are complementary with the positively charged structures of HLA DQ2, and HLA DQ8 antigens. The presentation of gluten proteins to T CD4+ lymphocytes leads to an escalation of the immune response, in which many specific autoantibodies are produced, and which are the basis of disease diagnostics. Among these autoantibodies, the following are routinely studied: anti-TTG $\operatorname{IgA} / \operatorname{IgG}$ antibodies, anti-endomysial antibodies IgA/IgG (EMA), and recently introduced antibodies against deaminated gliadin peptides DGP-IgG. The result 
of these processes is an inflammatory state within the intestinal wall, damage to the intestinal villi, and absorption impairment with a progressing malnutrition and related consequences [3].

Among environmental factors, the most important role is ascribed to an early introduction of gluten into the diet of a child. However, early provocation with gluten may also be advantageous to the establishment of immune tolerance, and may accordingly prevent the development of the disease. Therefore, according to the current dietetic recommendations, in breastfed children, gluten should be introduced into the diet between the $4^{\text {th }}$ and $6^{\text {th }}$ month of life, in the mode of gradually increased doses with concurrent observation of undesired events. Too late introduction of gluten into the diet may result in atypical picture of the disease, delay the diagnosis, or even make the disease undiagnosed for many years. The amount of gluten, and kind of gluten included in the diet seems to be equally important. Long-lasting infections in early childhood, as well as improper composition of intestinal flora are also taken into consideration as the factors participating in the ethiopathogenesis of the disease [3].

Diagnostics of celiac disease is complex, and it is based on clinical symptoms, serological tests detecting specific antibodies, and histopathologic studies of intestinal mucosa. In recent years, genetic studies identifying HLA DQ2/DQ8 antigens have been utilized more frequently. Due to the continuous increase in the knowledge of the disease, and a greater understanding of disease mechanisms, every couple of years, new recommendations on diagnostics and treatment of the disease are developed by expert groups $[4,5]$.

Based on clinical symptoms, antibodies profile and histopatological changes within the small intestine mucosa, several types of the disease were distinguished. The typical (classic) type which develops after the introduction of gluten into a diet, usually between $6^{\text {th }}$ and $24^{\text {th }}$ month of life, is characterized mainly by gastrointestinal symptoms (abdominal pain, diarrhea, vomiting, abdominal distention), and by insufficient body mass and height gain. In the atypical type, characteristic for older children and adults, many extraintestinal symptoms may appear. Skin lesions such as dermatitis herpetiformis, as well as osteoporosis, delayed puberty, short stature and anemia resistant to iron treatment, are believed to be closely connected with celiac disease. Moreover, the following afflictions are listed as related to celiac disease: hepatitis, arthritis, epilepsy and other neurological symptoms, chronic fatigue, infertility.

Apart from the systemic problems enumerated above, other pathological changes within the oral cavity, including particular enamel mineralization defects in permanent teeth and oral aphtous ulcers, may manifest themselves in the course of celiac disease.

Atypical celiac disease may progress in a latent form without any symptoms, and is frequently diagnosed in first degree relatives of celiac patients, in patients with diabetes and those with autoimmune diseases. A latent form occurs in older children and adults in whom typical morphological changes of intestinal mucosa and clinical symptoms related to gluten digestion were present in the past, and subsided after the introduction of glutenfree diet. These patients may, but do not have to show clinical symptoms. Similarly, autoantibodies specific for celiac disease may, but do not have to be present. A distinct type of the disease is celiac disease resistant to dietary treatment.

The risk of celiac disease increases in diabetes mellitus type 1 , Down syndrome, Williams syndrome, IgA deficiency, autoimmune thyroiditis, as well as in close relatives of a patient with celiac disease $[2,3]$. In the case of the presence of one of the diseases listed above, serologic screening tests should be performed, and if they are positive, further diagnostics should be performed according to the required standards. A particularly increased risk is connected with diabetes mellitus.

Serologic tests detecting specific antibodies: anti-tTG and anti-EMA of class IgA, or in the case of IgA deficiency of class IgG in the serum and histological examination of biopsy specimens of intestinal mucosa, are critical. The disappearance of clinical symptoms, regeneration of intestinal mucosa, and disappearance of antibodies after a gluten-free diet, which is currently the only mode of celiac disease treatment, confirm the diagnosis $[2,3]$. In the case of a diagnosis of celiac disease, a gluten-free diet should be recommended for the rest of the patient's life.

The oral cavity is one of the areas of celiac disease manifestation. Developmental defects of the dental enamel are especially frequently observed [6-19]. Impairment of dental crowns mineralization may occur in numerous systemic diseases. However, the changes in celiac disease are highly specific. According to Aine, they appear symmetrically and chronologically in the same anatomical groups of teeth in all 4 quadrants of dentition. Single and asymmetrical changes are regarded as highly unspecific for celiac disease [20]. These observations have been confirmed by other authors [7-10, 16]. Campisi et al. observed specific dental enamel lesions in $60 \%$ of patients with celiac disease, and only in $15 \%$ of those from the control group, and the difference was statistically significant [7]. 
Clinical picture of dental enamel structure defects in celiac patients may be diverse, and may contain hypoplasia (functional disturbances), as well as hypomineralization (qualitative disturbances) [21]. For the purpose of the assessment of those changes, a 4-grades classification proposed by Aine et al. is widely used [6]:

I. Single or multiple cream, yellow or brown opacities (marks) with clear or hazed boundary, part of the dental enamel may lack transparency,

II. Slight structural enamel defects, rough surface with horizontal groves or pits, distortion of enamel color and transparency,

III. Obvious structural defects of the dental enamel, part of the surface rough with deep groves of various depth, or with deep vertical pits, large opacities of different colors,

IV. Severe structural defects. The shape of the tooth changed. The tips of cusps are sharp-pointed and/or the incisal edges are unevenly thinned and rough. The thinning of the enamel material is easily detectable and the lesion may be strongly discolored

Electron microscope morphology analysis done by Bossu et al. showed a significant difference between enamel structure in celiac patients, and in healthy people (shorter enamel prisms more irregularly distributed, less interprismatic substance). According to the authors, the distinction of structural defects of the dental enamel in celiac disease may be used as an additional marker in the diagnostics of this disease [22].

In recent years, many studies confirming a higher frequency of dental enamel defects in patients with celiac disease than in healthy people have been published (Table 1). Trotta et al. have reported its ocurrence in as much $85.2 \%$ of adult patients [19]. Some authors suggest that there is a correlation between those changes and the age of patients [8, 9, 14]. Cheng et al. [9] observed that in children and teenagers, there is a higher frequency of dental enamel defects in the mixed dentition than in the permanent one. These changes occurred more frequently in teenagers than in adults. Such differences have not been observed in respective age groups of healthy people. From the analysis of logistic regression model used in those studies, a significant correlation of dental enamel developmental defects with age, celiac disease and mixed dentition appears. The lower frequency of dental enamel defects in adults may be caused by the fact that in many cases the development of celiac disease process might have taken place after the mineralization of dental crowns [9]. The process is based on gradual deposition of mineral substances on the organic matrix. In the case of deciduous teeth, the process begins in the prenatal period. Among permanent teeth, the teeth that undergo the mineralization process the earliest, i.e. in the perinatal period, are first molars, followed by incisors and canines (in the first year of life), then around the age of 2-2.5, premolars, and the age of 3 , second molars. The beginning of mineralization for the third molars is assumed for the age of 8-10. Crown calcification is a long process which ends in the period preceding teeth eruption. Therefore, it is believed that each systemic disease that occurs in the period of permanent or deciduous teeth mineralization, i.e. from the fourth month of the prenatal period till the age of 20 , may result in enamel

Table 1. Frequency of dental developmental defects in celiac disease

\begin{tabular}{|l|l|l|l|}
\hline \multirow{2}{*}{ Author (year) } & \multicolumn{2}{l|}{ Frequency of dental defects (patients vs. control group) } \\
\cline { 2 - 4 } & adults & children and teenagers & dentition studied \\
\hline Aine et al. (1990)[6] & 83 vs. $4 \%^{*}$ & & \\
\hline Bucci et al. (2006) [18] & & 20 vs. $6 \%^{*}$ & deciduous, permanent and mixed \\
\hline Wiernik et al.(2007) [10] & & 38 vs. $4 \%^{*}$ & deciduous and permanent \\
\hline Campisi et al. (2007) [7] & 23 vs. $8 \%^{*}$ & 23 vs. $9 \%^{*}$ & deciduous and mixed \\
\hline Ortega et al. (2008) [8] & & 83 vs. $53 \%^{*}$ & deciduous \\
\hline Postek-Stefańska et al. (2009) [12] & & 26 vs. $7 \%^{*}$ & deciduous, permanent and mixed \\
\hline Cheng et al. (2010) [7] & 32 vs. $29 \%$ & $\begin{array}{l}90 \text { vs. } 44 \%^{*} \\
34 \text { vs. } 25 \%\end{array}$ & deciduous, permanent \\
\hline Costacurta et al. (2010) [16] & & 33 vs. $11 \%^{*}$ & deciduous and mixed \\
\hline Acar et al.(2012) [11] & & 40 vs. $0 \%^{*}$ & deciduous and permanent \\
\hline Trotta et al. (2013) [19] & $85,2 \%$ & & permanent \\
\hline
\end{tabular}

* statistical significance. 
Table 2. Frequency of RAS in celiac disease

\begin{tabular}{|l|l|l|}
\hline Author (year) & Frequency of RAS (patients vs. control group) & Age group \\
\hline Bucci et al. (2006) [18] & 33 vs. $23 \%$ & children \\
\hline Campisi et al. (2007) [7] & 21 vs. $0,5 \%^{*}$ & children and adults \\
\hline Postek-Stefańska et al. (2009) [12] & 8 vs. $0 \%^{*}$ & children \\
\hline Costacurta et al. (2010) [16] & 8 vs. $3 \%^{*}$ & children \\
\hline Cheng et al. (2010) [9] & 42 vs. $23 \%^{*}$ & children and adults \\
\hline Acar et al. (2012) [11] & 37 vs. $11 \%^{*}$ & children \\
\hline
\end{tabular}

* statistical significance.

abnormalities. Their placement in specific anatomical groups of teeth, as well as their intensity depend on the age at which the pathological factor started to affect the teeth, and the period of its operation [23]. Studies of Mina et al. conducted on a group of Argentinian children with celiac disease did not show more frequent developmental dental defects in this population. However, in most of the cases, celiac disease had been diagnosed already before the end of the first year of life. According to the authors, an early introduction of a gluten-free diet might have prevented the disturbances of dental enamel mineralization [24].

It can be inferred from many reports that the observed developmental enamel changes have not been advanced, and the changes have been classified as the first or second degree according to Aine $[9-12,16,19,25]$. Trotta et al. have observed a tendency for a more frequent occurrence of advanced lesions (of the $3^{\text {rd }}$ and $4^{\text {th }}$ degree) among adult patients suffering from classical celiac disease. However, the dependency was not statistically significant [19].

Most frequently, those changes were observed in incisors, molars (especially in the first molars in the permanent dentition) and canines $[8,9,16]$.

The mechanism of dental enamel defects in celiac disease is not completely resolved. The role of nutritional, genetic and immunological factors is taken into consideration. It is thought that nutritional deficiency (especially hypocalcemia) caused by malabsorption may disturb the process of amelogenesis [26]. Reports on lower serum calcium concentration may be found in the literature [27].

There have also been reports on the relation of the occurrence of enamel disorders and the presence of certain HLA haplotypes among celiac patients. According to Mariani et al. the presence of a specific antigen - HLA-DR3, causes a significant increase in the risk of dental enamel development defects [28]. Erriu et al. in turn, have observed a significant positive correlation between the expression of HLA-DQB1 ${ }^{\star} 02$ and the defects in question [29].

Interesting results which may at least partially explain the disturbance of dental enamel maturation have been obtained in in vitro studies by Munoz et al. They observed that anti-gliadin antibodies, present in celiac patients, may react with proteins of the enamel matrix (amelogenin and ameloblastin). The cause of that is probably the similarity of amino acids composition of gliadin and that of enamel proteins with a particularly high content of proline which, in turn, together with glutamine, is to be responsible for immunological properties of gliadin in genetically predisposed people [30].

Despite the fact that the causes of typical dental enamel defects in patients with celiac disease are not completely explained, it is undisputable that these defects are frequent in such patients. Therefore, North American Society of Pediatric Gastroenterology, Hepatology and Nutrition has recognized dental enamel defects in permanent dentition as one of the symptoms which may have a direct connection with celiac disease [2]. These defects may be the sole symptom of celiac disease in children [6].

Lesions in the enamel structure similar to those observed in the course of celiac disease may occur independently of the disease. The differentiation should include molar incisor hypomineralization $(\mathrm{MIH})$. This disorder is treated as a separate disease entity of unknown etiology. The clinical picture of enamel defects is similar in the case of celiac disease. The only difference is that they may involve one or more permanent molars and incisors. If symmetrical lesions within the same group of teeth in 4 quadrants were to be identified, it would be recommended to perform medical tests for celiac disease be carried out [23, 31, 32]. Other complications observed in the oral cavity in patients with celiac disease are disturbances within mucosa. Aphthae are observed particularly often (RAS 
- recurrent aphtous stomatitis) (Table 2) $[7,9,11$, $12,16,18]$. Cheng et al. directed attention to frequent coexistence of aphthaes, and disturbances of dental enamel mineralization [9]. According to Campisi et al., these changes may appear in the form of small multiple changes, or in the form of single larger aphtha [7]. Malnutrition is reported as a presumable cause of those changes, especially iron, folic acid and vitamin B12 deficiencies which are very frequent in patients who do not adhere to gluten free diet $[12,33]$. This thesis seems to be confirmed by the studies of Bucci et al. and Campisi, who observed an improvement in the condition of the oral mucosa after the introduction of a strict gluten free diet $[7,18]$.

RAS may occur not only in the course of many diseases (Crohn's disease and immunodeficiencies), but also in healthy people. However, attention should be paid to a possible link between aphthae and gluten intolerance, which is widespread in the human population, but frequently undiagnosed $[3,21]$. Apart from RAS, in patients with celiac disease other disturbances of oral mucosa such as ulceration, erythema, atrophic glossitis and subjective symptoms: pain and a burning sensation (particularly of the tongue) and dryness, were observed $[7,33]$. However, Lähteenoja et al. did not note a strict dependence of gluten-free diet, and subsiding of the complaints [33].

Some multisystem disorders may lead to a deterioration of peridental tissues. However, in the case of celiac disease, this has not been observed $[33,34]$.

The problem of caries in celiac disease has not been definitely explained yet. Costacurta et al. observed a more frequent occurrence of caries in patients with this disease [16]. Nevertheless, in the literature an opposite view is more frequent $[8,14$, $17,35,36]$. It may be the effect of better control over a diet, and a smaller number of snacks [36], as well as better oral cavity hygiene [13]. Some authors report on a smaller level of bacteria causing caries in the saliva of patients with celiac disease (Streptococcus mutans, Lactobacillus) [11]. However, other studies have not confirmed this fact [13]. In some studies, no significant correlation between celiac disease and caries and the difference in oral hygiene levels has been observed [11,24].

The next problem which is discussed, is the delay in tooth eruption in celiac disease. Data in the literature does not explain this problem unambiguously. Campisi et al. and Costacurta et al. observed a significantly more frequent occurrence of these kind of disturbances in children with celiac disease in comparison with healthy children $[7,16]$. According to Campisi et al., delayed dental eruption may, similarly to the failure to thrive, be a signal of malnutrition and requires diagnostics toward gluten intolerance [7]. Mina et al. did not observe a connection between the time of tooth eruption and celiac disease [24].

The decrease in the stature of children with celiac disease is reflected in the growth of the maxilla and mandible, which results in a high percentage of children with malocclusion [37]. Among the studied children, $38 \%$ required orthodontic consultation and prophylactic or corrective treatment [36]. The most frequent malocclusions in children with celiac disease included open bite, deep bite, crowding of teeth and the frequency of malocclusions depends on adherence to a gluten-free diet [15].

From the review of literature, it can be inferred that in the course of celiac disease various disorders within the oral cavity which should attract attention of a physician may be present. From the analyses of logistic regression models performed by various authors, it can be noted that a significant link with celiac disease may occur in the case of dental enamel defects [7-9], aphthae, and other disorders of oral mucosa [7], as well as salivary total protein concentration and molar $\mathrm{Ca} / \mathrm{P}$ ratio in saliva [38].

There is an agreement in the literature that dental enamel defects typical for celiac disease are characterized by symmetry, chronology and occurrence with the same groups of teeth (most frequently in incisors, and first permanent molars) in all dentition quadrants [20].

According to NASPGHAN, besides other findings, the defects described above are an indication to undergo a test towards gluten intolerance, even if no other symptoms are present [2]. It should be remembered that about $10 \%$ of first-grade relatives suffer from "silent" celiac disease. Also diabetes mellitus type 1 is strongly related to celiac disease. Screening tests should be performed in 3 stages. The presence of antigladin antibodies of class IgA and IgG which are unspecific, and may be present in other disorders, indicates the necessity of determining the titer of specific antiendomysial antibodies and antibodies against tissue transglutaminase (tTG). At the third stage, a biopsy of small intestine mucosa and histopathological study should be performed in order to confirm celiac disease [15]. Genetic examination for the presence of HLA-DQ2 and HLA-DQ8 antibodies is helpful, since the absence of those antigens virtually excludes the possibility of celiac disease.

Patients with celiac disease must be informed about a gluten free diet to which they have to adhere for the rest of their life. Unfortunately, about $30-70 \%$ of patients do not adhere to it periodically or entirely. It is also possible that celiac patients consume certain amounts of gluten unconsciously, 
due to contamination of gluten-free products. Dietary errors, or giving up a gluten-free diet after puberty, when spontaneous attenuation of symptoms is observed, carry a risk of malignant neoplasm of the alimentary tract, or other multisystem disorders during adulthood [39].

Diversity of clinical symptoms in celiac disease may be a cause of difficulties and diagnostic errors. Therefore, the knowledge of the disease among physicians from various medical specialties is of great importance, since they may help in the diagnostic process. Meticulous examination of the oral cavity with particular attention directed to dental enamel defects, aphthae and other mucosal disorders, as well as to delayed tooth eruption, may contribute to an early diagnosis of celiac disease and may help prevent its progress and complications.

\section{References}

[1] Marsh MN: Gluten, major histocompatibility complex and the small intestine. Gastroenterology 1992, 102, 330-354.

[2] Hill ID, Dirks MH, Liptak GS, Coletti RB, Fasano A, Guandalini S, Hoffenberg EJ, Horvath K, Murray JA, Pivor M, Seidman EG: Guideline for the diagnosis and treatment of celiac disease in children: recommendations of the North American Society for Pediatric Gastroenterology, Hepatology and Nutrition. J Pediatr Gastroenterol Nutr 2005, 40, 1-19.

[3] Rivera E, Assiri A, Guandalini S: Celiac Disease. Oral Dis 2013, doi: 10.1111/odi 12091, 1-7.

[4] Husby S, Koletzko S, Korponay-Szabo IR: ESPGHAN guidelines for the diagnosis of coeliac disease in children and adolescents. An evidence - based approach. J Pediatr Gastroenterol Nutr 2012, 54, 136-160.

[5] Iwańczak F, Iwańczak B: Nowe wytyczne dotyczące diagnostyki i leczenia choroby trzewnej u dzieci i młodzieży. Przegl Gastroenterol 2012, 7, 4, 185-191.

[6] Aine L, Mäki M, Collin P, Keyrilläinen O: Dental Enamel Defects in celiac disease. J Oral Pathol Med 1990, 19, 241-245.

[7] Campisi G, Di Liberto C, Iacono G, Compilato D, Di Prima L, Calvino F, Di Marco V, Lo Muzio L, Sferrazza C, Scalici C, Craxi A, Carroccio A: Oral pathology in untreated coeliac disease. Aliment Pharmacol Ther 2007, 26, $1529-1536$.

[8] Ortega Paez E, Junco Lafuente P, Baca Garcia P, Maldonado Lozano J, Llodra Calvo JC: Prevalence of dental enamel defects in celiac patients with deciduous dentition: a pilot study. Oral Surg Oral Med Oral Pathol Oral Radiol Endod 2008, 106, 74-78.

[9] Cheng J, Malahias T, Brar P, Minaya MT, Green PH: The association between celiac disease, dental enamel defects, and aphtous ulcers in a United States cohort. J Clin Gastroenterol 2010, 44, 191-194.

[10] Wiernik CD, van Diermen DE, Aartman IH, Heymans HS: Dental enamel defects in children with coeliac disease. Int J Paediatr Dent 2007, 17, 136-138.

[11] Acar S, Yetkiner AA, Ersin N, Oncag O, Aydogdu S, Arikan C: Oral findings and salivary parameters in children with celiac disease: a preliminary study. Med Princ Prac 2012, 21, 129-133.

[12] Postek-Stefańska L, Kalacińska J, Wacławczyk A, Kupczyński P: Stan zdrowia jamy ustnej u pacjentów z celiakią. Dent Med Probl 2009, 46, 168-176.

[13] Shetyer E, Berson T, Lachmanovitz O, Hidas A, Wilschanski M, Meneachem M, Shachar E, Shapira J, Steinberg D, Moskovitz M: Oral health status and salivary properties in relation to gluten free diet in children with celiac disease. J Pediatr Gastroenterol Nutr 2013, 57, 1, 49-52.

[14] Farmakis E, Puntis JW, Toumba KJ: Enamel defects in children with coeliac disease. Eur J Paediatr Dent 2005, 6, 129-132.

[15] Skrzelewska K, Czerwonka-Szaflarska M: Analiza zmian w jamie ustnej u dzieci, młodzieży i dorosłych z chorobą trzewną. Przegl Pediatr 2004, 34, 21-25.

[16] Costacurta M, Maturo P, Bartolino M, Docimo R: Oral manifestation of coeliac disease. Oral Implantol 2010, 3 , 12-19.

[17] Priovolou CH, Vaderas AP, Papaginnoulis L: A comparative study on the prevalence of enamel defects and dental caries in children and adolescents with and without coeliac disease. Eur J Paediatr Dent 2004, 5, 102-106.

[18] Bucci P, Carile F, Sangianantoni A, D’Angio F, Santarelli A, Lo Muzio L: Oral aphtosus ulcers and dental enamel defects in children with coeliac disease. Acta Paediatr 2006, 95, 203-207.

[19] Trotta L, Biagi F, Bianchi PI, Marchese A, Vattiato C, Balduzzi D, Collesano V, Corazza GR: Dental enamel defects in adult coeliac disease: prevalence and correlation with symptoms and age at diagnosis. Eur J Intern Med 2013, 24, 832-834.

[20] Aine L: Dental enamel defects and dental maturity in children and adolescents with coeliac disease. Proc Finn Dent Soc 1986, 82, 1-71.

[21] Rashid M, Zarkadas M, Anca A, Limeback H: Oral manifestations of coeliac disease: a clinical guide for dentists. J Mich Dent Assoc 2011, 93, 42-46.

[22] Bossu M, Bartoli A, Orsini G, Luppino E, Polimeni A: Enamel hypoplasia in coeliac children: a potential clinical marker of early diagnosis. Eur J Paediatr Dent 2007, 8, 31-37.

[23] Cameron AC: Stomatologia dziecięca. Elsevier Urban\&Partner, Wrocław 2008, wyd. 3, 248-257, 458-459.

[24] Mina SS, Azcurra AI, Dorronsoro S, Brunotto MN: Alterations of the oral ecosystem in children with celiac disease. Acta Odontol Latinoam 2008, 21, 121-126. 
[25] Avsar A, Kalayci AG: The presence and distribution of enamel defects and caries in children with celiac disease. Turk J Pediatr 2008, 50, 45-50.

[26] Nikiforuk G, Fraser D: The etiology of enamel hypoplasia: a unifying concept. J Pediatr 1981, 98, 888-893.

[27] El-Hodhod MA, El-Agouza IA, Abdel-Al H, Kabil NS, Bayomi KA: Screening for celiac disease in children with dental enamel defects. ISRN Pediatr 2012, 763783. doi: 10.5402/2012/763783.

[28] Mariani P, Mazilli MC, Margutti G, Lionetti P, Triglione P, Petronzelli F: Coeliac disease, enamel defects and HLA typing. Acta Paediatr 1994, 83, 1272-1275.

[29] Erriu M, Abbate GM, Pili FM, Novara F, Orru G, Montaldo C, Piras V, Levrini L: Oral signs and HLADQB1 ${ }^{\star} 02$ haplotypes in the celiac paediatric patient: a preliminary study. Autoimmune Dis 2013, 389590. doi:10.1155/2013/389590.

[30] Muňoz F, Del Rio N, Sónora C, Tiscornia I, Marco A, Hernandez A: Enamel defects associated with coeliac disease: putative role of antibodies against gliadin in pathogenesis. Eur J Oral Sci 2012, 120, 104-112.

[31] Condo R, Perugia C, Maturo P, Docimo R: MIH: epidemiologic clinic study in paediatric patient. Oral Implantol 2012, 5, 58-69.

[32] Lygidakis NA, Wong F, Jälevik B, Vierrou AM, Alaluusua S, Espelid I: Best clinical practice guidance for clinicians dealing with children presenting with Molar-Incisor Hypomineralization (MIH): an EAPD policy document. Eur Arch Paediatr Dent 2010, 11, 75-81.

[33] Lähteenoja H, Toivanen A, Viander M, Mäki M, Irjla K, Rähä I, Syrjänen S: Oral mucosal changes in coeliac patients on a gluten free diet. Eur J Oral Sci 1998, 106, 899-906.

[34] Tsami A, Petropoulou P, Panayiotou J, Mantzavinos Z, Roma-Giannikou E: Oral hygiene and periodontal treatment needs in children and adolescents with coeliac disease in Greece. Eur J Paediatr Dent 2010, 11, 122-126.

[35] Pastore L, Carroccio A, Compilato D, Panzarella V, Serpico R, Lo Muzio: Oral manifestations of celiac disease. J Clin Gastroenterol 2008, 42, 224-232.

[36] Marzec-Koronczewska Z: Stan narządu żucia u dzieci z glutenozależną chorobą trzewną. Czas Stomatol 1990, 43, 207-212.

[37] Romankiewicz-Woźniaczko G, Erecińska K, Kaczmarczyk J: Stan jamy ustnej u dzieci po przebytej celiakii. Wiad Lek 1973, 26, 1011-1017.

[38] Mina SS, Azcurra AI, Riga C, Cornejo LS, Brunotto M: Evaluation of clinical dental variables to build classifiers to predict celiac disease. Med Oral Patol Oral Cir Bucal 2008, 13, 398-402.

[39] Czerwionka-Szaflarska M: Choroba trzewna - celiakia. Openmedica Zdrowie 2002.02.12.

\section{Address for correspondence:}

Małgorzata Kowalczyk-Zając

Department of Conservative Dentistry and Pedodontics

Wroclaw Medical University

Krakowska 26

50-425 Wrocław

Poland

Tel.: +48 605760019

E-mail: goskazajac@hotmail.com

Conflict of interest: None declared

Received: 22.07 .2013

Revised: 7.02.2014

Accepted: 17.09.2014 